\title{
Pedagogia da Alternância como proposta emancipadora na educação do campo
}

\author{
Alternating cycle pedagogy as an emancipating proposal in countryside education \\ La pedagogía del ciclo alterno como propuesta emancipadora en la educación del campo
}

Recebido: 24/01/2022 | Revisado: 31/01/2022 | Aceito: 06/02/2022 | Publicado: 11/02/2022

\author{
Diana Da Silva Ribeiro \\ ORCID: https://orcid.org/0000-0001-7938-2467 \\ Universidade Federal do Amazonas, Brasil \\ E-mail: dyanasr25@gmail.com \\ Eulina Maria Leite Nogueira \\ ORCID: https://orcid.org/0000-0002-7725-6464 \\ Universidade Federal do Amazonas, Brasil \\ E-mail: eleite@ufam.edu.br \\ Bruna Dos Santos Prata \\ ORCID: https://orcid.org/0000-0002-2023-3704 \\ Universidade Federal do Amazonas, Brasil \\ E-mail: brunaprata05@gmail.com \\ Aline Lucas de Souza Gomes \\ ORCID: https://orcid.org/0000-0001-7166-0944 \\ Universidade Federal do Amazonas, Brasil \\ E-mail: alinenila76@gmail.com
}

\begin{abstract}
Resumo
O texto ora apresentado traz as contribuições epistemológicas de uma pesquisa em andamento, no Mestrado em Ensino de Ciências e Humanidades, da Universidade Federal do Amazonas. O objetivo é fazer uma contextualização histórica do objeto de estudo, refletindo sobre o ato de educar para a libertação do homem e da mulher do campo. A metodologia utilizada é qualitativa e bibliográfica, com vistas a analisar a proposta da pedagogia da alternância na Escola Família Agrícola. Os resultados parciais mostram que o modelo de ensino da pedagogia da alternância surgiu na França, em 1935, constitui-se como uma experiência de educação que busca romper com o modelo de produção capitalista, para o fortalecimento de alternativas baseadas na ecologia, emancipação das identidades camponesas e seus territórios agrícolas. A proposta da pedagogia da alternância como instrumento de ensino e aprendizagem está inserida na educação do campo, a partir dos anseios e lutas de sujeitos que protagonizaram diversas experiências de educação voltada para a realidade da vida das populações que vivem em contexto rurais.
\end{abstract}

Palavras-chave: Educação do campo; Pedagogia da alternância; Escola Família Agrícola.

\begin{abstract}
The text now presented brings the epistemological contributions of a research in progress in the Master's Degree in Science and Humanities Teaching, Federal University of Amazonas. The goal is to make a historical contextualization of the object of study, reflecting on the act of educating for the liberation of the countryside men and women. The methodology used is qualitative and bibliographical, aiming to analyse the proposal of the Alternating Cycle Pedagogy in the Family Agricultural School. The partial results show that the teaching model of the alternance pedagogy emerged in France in 1935, constitutes an educational experience that seeks to break with the model of capitalist production, for the strengthening of alternatives based on ecology, emancipation of peasant identities and their agricultural territories. The proposal of the Alternating Cycle Pedagogy as an instrument of teaching and learning is inserted in rural education, based on the desires and struggles of individuals who have led diverse experiences of education aimed at the reality of life of the populations who live in rural contexts.
\end{abstract}

Keywords: Rural education; Alternating Cycle Pedagogy; Agricultural Family School.

\section{Resumen}

El texto que aquí se presenta trae los aportes epistemológicos de una investigación en curso en la Maestría en Enseñanza de Ciencias y Humanidades, de la Universidad Federal de Amazonas. El objetivo es hacer una contextualización histórica del objeto de estudio, reflexionando sobre el acto de educar para la liberación de los hombres y mujeres del campo. La metodología utilizada es cualitativa y bibliográfica, con el objetivo de analizar la propuesta de la Pedagogía de Ciclo Alterno en la Escuela Familiar Agraria. Los resultados parciales muestran que el modelo de enseñanza de la pedagogía de la alternancia surgido en Francia en 1935, constituye una experiencia educativa que busca romper con el modelo de producción capitalista, para el fortalecimiento de alternativas basadas en la ecología, la emancipación de las identidades campesinas y sus territorios agrícolas. La propuesta de la pedagogía de la alternancia como instrumento de enseñanza y aprendizaje se inserta en la educación rural, a partir de los anhelos 
y luchas de personas que han protagonizado diversas experiencias de educación dirigidas a la realidad de la vida de las poblaciones que viven en contextos rurales.

Palabras clave: Educación rural; Pedagogía de ciclo alterno; Escuela de família agrícola.

\section{Introdução}

Por epistemologia compreende-se a abordagem sobre o conhecimento, uma afirmação validada ou justificada, pois o que caracteriza o científico é o processo de validação através do método rigoroso. A consciência humana é reflexiva, podendo o ser humano refletir sobre as questões do mundo a sua volta. Este estudo traz reflexões sobre a proposta da pedagogia da alternância na Escola Família Agrícola (EFA), bem como enfatiza, com aporte teórico crítico, as contribuições epistemológicas da pesquisa em andamento, na área de ensino, no Mestrado em Ensino de Ciências e Humanidades, da Universidade Federal do Amazonas.

Ao tratar do tema da educação, ressalta-se que "todo processo educativo envolve, pois, uma relação de poder em seu conceito mais geral, seja em estado potencial, seja em estado atual. Em princípio, essa relação pode dar-se tanto como podersobre quanto como poder-fazer" (Paro, 2010, p. 46). Assim, a pesquisa ora apresentada tem como ponto de partida experiências vivenciadas no cotidiano de uma EFA e está inserida no poder-fazer para a liberdade dos educandos. A metodologia norteadora das EFA é a pedagogia da alternância, nas palavras de Nosella (2014 p. 29) "a particularidade mais característica desse amplo movimento das escolas da família agrícola se define pela expressão pedagogia da alternância”.

Portanto, a EFA é uma organização comunitária, pautada na pedagogia da alternância, com a perspectiva de promover o desenvolvimento sustentável e solidário do campo dentro do ambiente educacional. Trata-se de uma entidade educacional de promoção social, sem fins lucrativos, originada dos anseios da comunidade, dos agricultores e agricultoras, sindicatos e movimentos sociais.

Normalmente, as EFA possuem uma associação local, atrelada a uma associação regional. A associação regional tem ligação com a União Nacional das Escolas Famílias Agrícolas do Brasil (UNEFAB), que, por sua vez, se vincula à Associação Internacional de Movimentos Familiares de Formação Rural (AIMFR). Assim, esse modelo tem organização tanto na esfera local, estadual, como em nível nacional e internacional.

A pesquisa ora em andamento trará contribuições epistemológicas relevantes para a educação, por se tratar de uma proposta social importante para a formação na perspectiva socialista, emancipadora e de libertação das massas. Nesse sentido, Costa (2007, p. 116) afirma que "[...] criar um problema de pesquisa é virar a própria mesa, rachando os conceitos e fazendo ranger a articulação das teorias”.

O conhecimento produzido contribuirá para o reconhecimento de uma modalidade de educação que tem como base a convivência, a troca de experiências entre os estudantes, a realidade da vida e a transformação do tecido social. A pesquisa pretende promover um debate sobre o direito à educação, pois, como prevê o artigo 205 da Constituição do Brasil, “a educação, direito de todos e dever do Estado e da família, será promovida e incentivada com a colaboração da sociedade, visando ao pleno desenvolvimento da pessoa, seu preparo para o exercício da cidadania e sua qualificação para o trabalho" (Brasil, 1988).

Nesse contexto, a proposta da pedagogia da alternância enfatizada neste estudo, contribui para uma educação, direito de todos, especialmente, se dedica a educação do campo. No desenvolvimento da pesquisa, a abordagem do conhecimento, promoverá o debate sobre uma proposta de educação transformadora. Essas análises foram feitas durante o curso de Mestrado em Ensino de Ciências e Humanidades, na disciplina de Epistemologia, no ano de 2021. O curso de Mestrado citado, ofertado pela Universidade Federal do Amazonas possibilita uma abordagem interdisciplinar do conhecimento, tem área de concentração em Ensino de ciências e humanidades, contemplando tantos as ciências humanas como as ciências naturais e 
matemática. A pesquisa apresentada está inserida na linha 1 do programa, Perspectivas teórico-metodológicas para o ensino das ciências humanas.

Dado que "o papel do pesquisador é justamente o de servir como veículo inteligente e ativo entre esse conhecimento construído na área e as novas evidências que serão estabelecidas a partir da pesquisa" (Lüdke \& André, 2013, p. 26), o desenvolvimento deste artigo traz contribuições relevantes para as ciências humanas e sociais, ao apresentar uma perspectiva de educação decolonial, tão necessária neste século XXI.

\section{Metodologia}

O caminho metodológico foi orientado pela abordagem de cunho qualitativo, resultado do aprofundamento teórico e pesquisa bibliográfica realizados durante a oferta da disciplina de Epistemologia, do curso de Mestrado em Ensino de Ciências e Humanidades (2021), sendo que a análise dos dados foi produzida durante a disciplina, na Universidade Federal do Amazonas, tendo como referência a abordagem social, em que ressalta-se a obra de Minayo (2002), fundamental para construção metodológica.

A escolha da pesquisa qualitativa ocorreu pelo fato dessa abordagem responder a questões muito específicas de um objeto de estudo. Nas ciências sociais, ela se preocupa com as inter-relações, um nível de realidade com a visão do microsocial.

A pesquisa qualitativa responde a questões muito particulares. Ela se preocupa, nas ciências sociais, com um nível de realidade que não pode ser quantificado. Ou seja, ela trabalha com o universo de significados, motivos, aspirações, crenças, valores e atitudes, o que corresponde a um espaço mas profundo das relações, dos processos e dos fenômenos que não podem ser reduzidos à operacionalização das variáveis (Minayo, 2002, p. 21).

Além disso, a pesquisa de base teórica, de natureza qualitativa descritiva, possibilitou a compreensão de fenômenos sociais na educação sendo importante, ainda, para analisar aspectos da realidade histórica e social. A construção dos dados dialoga com a tendência pedagógica libertadora, de Paulo Freire (2014), em que a educação proposta, possibilita a transformações de realidades sociais, emancipação do ser humano, se contrapondo a concepção de uma educação bancária.

Quanto ao conceito de educação do campo utilizado, teve como paradigma o que foi construído dentro dos movimentos sociais, tendo como principal referencial teórico Caldart (2002). Assim, a escolha metodológica vai ao encontro do objeto de estudo analisado.

\section{Resultados e Discussão}

A proposta da pesquisa em andamento surgiu do anseio de construir novos conhecimentos acerca de um método de ensino originado na França, no ano de 1935, visando atender a povos historicamente marcados pela luta pelo direito à educação. Trata-se de uma proposta de ensino originalmente destinada às populações do campo que - mediante a inexistência de um modelo educacional que atendesse às necessidades dos filhos de agricultores e agricultoras - fundaram a primeira EFA na França (1935), visando desenvolver uma metodologia para o contexto rural e seu desenvolvimento. Segundo Vergutz e Cavalcante (2014, p. 373),

O cenário no qual emerge a Pedagogia da Alternância tem suas origens na década de 30, na França, embasada nas necessidades do povo camponês de uma educação voltada para sua realidade e suas necessidades. Isto acontece em virtude de que o mundo ocidental pós- revolução industrial passa a ter como característica fundante a valorização da cidade sobre o campo, aumentada com as Guerras Mundiais que, na Europa, contribuem para a proliferação de atividades urbanoindustriais, causando o êxodo rural. 
No Brasil, esse método tem como principais apoiadores o professor Paolo Nosella, cujas contribuições são relevantes para a compreensão da metodologia da alternância (2012), além de dialogar com a teoria de Paulo Freire (2014), ao propor uma educação pensada no oprimido, na busca da conscientização histórica e transformação das realidades injustas. Conforme a Proposta de Regulamentação da Pedagogia da Alternância, do Ministério da Educação (MEC) (Brasil, 2020), tem-se que:

A Alternância é uma prática formativa construída inicialmente no âmbito do Movimento da Educação do Campo no final da década de 1980 e se constitui como uma estratégia teórico- metodológica de formação dos sujeitos ancorada na relação Trabalho-Educação-Território. Trata-se de um processo educativo potencializador das dimensões que são estruturantes das formas de produzir e reproduzir a existência no contexto rural. As experiências em expansão demonstram a força da Pedagogia da Alternância pelas possibilidades oferecidas na conjugação da formação teórica com as atividades na realidade de vida e trabalho. Ela se constitui uma iniciativa importante para contribuir com os processos de formação dos sujeitos e de desenvolvimento sustentável das escolas do campo, do cerrado, das águas e das florestas (Brasil, 2020, p. 2-3)

A proposta da pedagogia da alternância está inserida na educação do campo, nos anseios e lutas de vários sujeitos que protagonizaram diversas experiências de educação voltada para a realidade em que vivem. Na concepção de Medeiros (2012, p. 52), “a educação do campo ganha expressão pela mobilização dos povos do campo seja nos movimentos sociais e organizações sindicais, seja em outras entidades populares”. Os movimentos sociais emergem da organização de base social coletiva, constituindo importantes ferramentas para a mudança social e histórica de realidades injustas. Normalmente, esses movimentos e organizações congregam pessoas em torno de objetivos e anseios comuns.

Miranda (2009, p. 1) considera que "uma sociedade pode ser vista sob dois aspectos aparentemente opostos - os fatores de manutenção da ordem social, relacionados às tradições, e suas forças de transformação, relacionadas à mudança social". Na realidade histórica, os movimentos sempre existiram, representando as forças sociais organizadas, reunindo as pessoas não como força-tarefa de ordem numérica, mas como campo de atividades e experimentação social. Essas atividades são fontes geradoras de criatividade e inovações socioculturais. A experiência da qual são portadores não advém de forças congeladas do passado, mesmo que este tenha importância crucial ao criar uma memória que, quando resgatada, dá sentido às lutas do presente (Gohn, 2011).

Assim, pode-se dizer que as organizações comunitárias e de caráter popular são formas de resistência e que buscam compreender o espaço social, exercem um papel fundamental na construção de um novo paradigma para a educação voltada a realidade do campo, que visa atender às reais necessidades dos sujeitos de identidade camponesa. Conforme diz Campos (2007, p. 12), “o desafio que se coloca para a educação é o de intervir no mundo, transformando-o pelo diálogo". A pedagogia da alternância tem se destacado nos movimentos sociais, por ter métodos e técnicas apropriados para a realidade do campesinato, promovendo o desenvolvimento dessa realidade, propiciando formação humana integral, emancipação das identidades camponesas e desenvolvimento do território na perspectiva ecológica. Na visão de Saviani (2014, p. 32),

Diante da sociedade capitalista, a experiência das Escolas da Família Agrícola vem realizando, assim, um movimento semelhante àquele do MST que, aliás, também tem defendido, em certas circunstâncias, a organização do ensino nos moldes da pedagogia da alternância. Dessa forma, em lugar de buscar assegurar seu espaço na sociedade capitalista enquanto pequenos proprietários agrícolas, o movimento dos agricultores toma consciência de que seus interesses e necessidades, em última instância, só poderão ser atendidos com a superação desta forma social e organização de uma nova sociedade confluindo, assim, para a perspectiva socialista que pressupõe a abolição da propriedade privada. 
Desse modo, é através da luta contínua que agricultores e agricultoras vêm conquistando seu espaço, rompendo com a lógica imposta pelo capital, para uma produção ecológica e sustentável, considerando-se que, "quanto mais avançada a sociedade capitalista, mais unilateralmente centrada na produção de riqueza reificada com um fim em si mesma e na exploração das instituições educacionais de todos os níveis" (Mészáros, 2008, p. 80). O movimento dos pequenos proprietários agrícolas ganha força e identidade a partir do momento em que eles tomam consciência dos seus direitos, de sua situação histórica, da exploração nos territórios agrícolas.

De acordo com Kolling, Ceriolli e Caldart, (2002, p. 18),

Um dos traços fundamentais que vêm desenhando a identidade deste movimento por uma educação do campo é a luta do povo do campo por políticas públicas que garantam o seu direito à educação, e a uma educação que seja no e do campo. No: o povo tem direito a ser educado no lugar onde vive; Do: o povo tem direito a uma educação pensada desde o seu lugar e com a sua participação, vinculada à sua cultura e às suas necessidades humanas e sociais.

Assim sendo, a pedagogia da alternância adquiriu força no Brasil, pois é uma forte aliada para a emancipação do homem e da mulher do campo, construtores de conhecimento, das formas de plantio e colheita. Podemos dizer que é uma pedagogia centrada na libertação dos oprimidos e "para superar a situação de opressão, o ser humano precisa, primeiramente, reconhecer criticamente a sua causa, de modo que por meio da ação transformadora, ele possa criar uma nova situação social, política e cultural" (Bauer, 2008, p. 97)

A conscientização é fundamental no processo de libertação do ser humano, para formar pessoas verdadeiramente livres. Quanto mais homens e mulheres forem livres, maiores são as chances de lutar contra a dominação, pois "quando as classes subjugadas se organizam, se apropriam da política e se educam para criar uma nova concepção de hegemonia" (Semeraro, 2006, p. 32). Nessa perspectiva, a presente pesquisa, na área de ensino, versa sobre a proposta da pedagogia da alternância no contexto da EFA, em um movimento dialético, reconstruindo as origens da experiência e percebendo as nuances do seu desenvolvimento e aplicabilidade em sala de aula. Segundo Silva (2017, p. 17),

Os teóricos críticos nos apontam que um dos espaços de resistência ao poder ideológico é o espaço da sala de aula, na mudança da consciência ingênua para a consciência crítica na medida em que o educador desafia o educando a pensar sobre a realidade e a buscar transformá-la coletivamente, dentro de suas possibilidades históricas concretas. Contribuir com o processo de desnaturalização e desmistificação do contexto em que se está imerso, de modo a transcender tal realidade, é um dos passos possíveis para evitar a aculturação, o domínio e o autoritarismo. Por meio do trabalho formativo filosófico, são oportunizadas as condições para que o aluno seja capaz de emergir de uma "pseudoconsciência", de uma consciência alienada, para assumir os riscos de uma tomada de postura crítica frente ao mundo.

Neste estudo, entende-se que o ato de pesquisar, tendo como ponto de partida o cotidiano de uma EFA, significa construir novos conhecimentos sobre experiências educacionais que contribuem para a libertação das massas populares. Nas palavras de Costa (2007, p. 117),

Os instrumentos para a constituição de um problema de pesquisa- com os quais montamos as estratégias e táticas dessa guerrilha de suspeição- não podem ser outros que os das teorizações que já foram construídas. Por isso, a nosso modo, e com os limites, temos o dever de nos apropriar - pela via do estudo- dos territórios teóricos e com eles estabelecer interlocuções, ao mesmo tempo em que vamos reelaborando as teorias.

Sendo assim, esta pesquisa vai sendo construída no diálogo no campo teórico-crítico e com base na dialética em que "a investigação assume, portanto, a criação investigativa, dita científica, como própria da criação literária e artística" (Costa, 
2007 p. 121). Nesse sentido, a pedagogia da alternância possibilita uma reflexão crítica sobre a realidade da população em que se encontra inserida, pois possibilita diversas experiências no percurso formativo ao longo de tempo e espaços diversos, com o objetivo de formação integral do sujeito do campo. Nessa perspectiva, Frigotto e Ciavatta (2005 p.24) afirmam que "os processos educacionais têm o mercado e o capital como medida de tudo, em função do privilégio de poucos. Mas, a história vem mostrando que eles podem constituir-se em instrumento de críticas em relação a essas relações sociais"

O que se espera, portanto, é contribuir para novas epistemologias a partir do conhecimento produzido sobre uma outra educação possível, presente em vários países do mundo. No Brasil, esse modelo assume a perspectiva baseada na dialética, resultado das lutas de classe, em que se desafia a didática sustentada no capitalismo, para construir uma nova história da educação nos espaços de luta e resistência camponesa, como instrumento de crítica a educação hegemônica.

Por considerar a escola uma das organizações da sociedade civil responsáveis por elaborar e difundir ideologias, Gramsci (citado Ferretti, 2009, p. 120) percebe nela tanto a possibilidade de reiteração da concepção de mundo das classes dominantes, quanto a de atuação no sentido de contribuir para a reforma intelectual-moral da massa trabalhadora, tendo por horizonte a superação da sociedade capitalista.

Mediante a atual situação das populações do campo no Brasil, cabe enfatizar que atualmente se vive um retrocesso em relação os direitos e garantias conquistadas. A atual conjuntura é de ascensão do neoliberalismo e das práticas voltada ao lucro e à exploração dos territórios agrícolas, visando à produção baseada no agronegócio, gerando capital. As consequências dessa hegemonia ficam evidentes no enfraquecimento das políticas para a educação do campo, que deve ser uma educação pensada no desenvolvimento humano e sustentável, com práticas de ensino emancipatória, que questionam o modelo de educação do capital, para que a população do campo cada vez mais tome consciência de sua situação histórica.

No Brasil, a violência no campo tem aumentado consideravelmente e isso está relacionado com o atual momento histórico de enfraquecimento da democracia brasileira, com os conflitos no campo e crescente violência materializados em assassinatos, tentativas de assassinatos, ameaças, pistolagem, expulsões, despejos e destruição de bens de populações camponesas, dos povos indígenas e quilombolas, segundo a publicação anual do Caderno de Conflitos no Campo Brasil, a cargo da Comissão Pastoral da Terra (CPT) (Júnior, 2017, p. 1)

As propostas de educação pautada na pedagogia da alternância se contrapõem a essa violência perpetrada contra os povos do campo. Apresenta-se como uma educação crítica, ética, política, sustentada em uma visão de produção agroecológica e preservação da vida, buscando a emancipação das populações camponesas.

No momento atual de crescente avanço do agronegócio, essa proposta pode encontrar-se enfraquecida em algumas regiões do Brasil, o que tem refletido de forma negativa na estrutura e organização de algumas EFA, como é o caso da EFA Vale do Guaporé, em Rondônia, que tem mudado consideravelmente sua estrutura enquanto modelo de ensino que surgiu de base popular, assumindo uma nova configuração que aos poucos, vai deixando para trás princípios de agroecologia e sustentabilidade, para abrir espaço à nova realidade da região do estado de Rondônia, com o avanço do agronegócio.

\section{Considerações Finais}

Considerando o diferencial da educação do campo e da pedagogia da alternância na EFA, esta pesquisa será relevante para as ciências humanas e sociais, para uma teoria crítica da educação, interagindo com o processo histórico da conquista dos movimentos sociais, de trabalhadores rurais, movimentos de educadores e vários outros sujeitos envolvidos na busca por uma educação emancipadora, que rompa com o paradigma de uma educação hegemônica baseada no capital. Ressalta-se ainda, que o artigo possibilita uma abordagem do conhecimento, que está sendo produzido na Universidade Federal do Amazonas, que posteriormente resultará na dissertação de Mestrado, inserida na linha 1 do programa- Perspectivas teórico-metodológicas para o ensino das ciências humanas. 
A pedagogia da alternância é um método de ensino, que tem se demonstrado eficaz para os povos do campo. $\mathrm{O}$ ato de pesquisar visa, sobretudo, promover o reconhecimento desse modelo de ensino e a sua contribuição para a sociedade. Significa trazer para a ciência a concepção de mundo de sujeitos historicamente negligenciados, pessoas que se organizam e desafiam a lógica da educação burguesa, desafiam a própria filosofia da educação existente, criando outras possibilidades e metodologias de ensino, sendo os protagonistas de um novo ensino que emana da luta de classes para transformar a sociedade.

Assim, a proposta da EFA pode ser considerada uma possibilidade de formação de trabalhadores rurais, ribeirinhos, quilombolas, indígenas, pescadores etc. pautada no compromisso social de sustentabilidade e de formação política, respeitando a cultura de cada lugar, seu tempo e espaço na produção da vida no campo, utilizando a pedagogia da alternância como metodologia de ensino e aprendizagem de todos os atores que compõem a EFA, buscando a transformação social de sua população.

\section{Referências}

Bauer, C. (2008). Introdução crítica ao humanismo dialógico de Paulo Freire. Instituto José Luís e Rosa Sundermann.

Brasil. (1988). Constituição da república federativa do Brasil de 1988._http://www.planalto.gov.br/ccivil_03/constituicao/constituicao.htm.

Brasil, (2012). Ministério da Educação. Secretaria de Educação Continuada, Alfabetização, Diversidade e Inclusão - SECADI. Educação do campo: marcos normativos/Secretaria de Educação Continuada, Alfabetização, Diversidade e Inclusão. Brasília: SECADI, 2012. http://pronacampo.mec.gov.br/images/pdf/bib_educ_campo.pdf.

Brasil, (2020). Ministério da Educação. Conselho Nacional de Educação. Câmara de Educação Básica. Proposta de regulamentação da pedagogia da alternância. Brasília, 2020. http://portal.mec.gov.br/index.php?option=com_docman\&view=download\&alias=146891-texto-referencia-pedagogia-daalternancia\&category_slug=junho-2020-pdf\&Itemid=30192.

Caldart, R. S. (2012). (Org.). Dicionário da educação do campo. Rio de Janeiro: Escola Politécnica de Saúde Joaquim Venâncio; São Paulo: Expressão Popular, 2012. http://www.epsjv.fiocruz.br/sites/default/files/l191.pdf.

Campos, C. M. (2007). Saberes docentes e autonomia dos professores. Vozes.

Costa, M. V. (2007). (Org.). Caminhos investigativos I: Novos olhares na pesquisa em educação. (3a ed.) Lamparina.

Ferretti, C. J. (2009). O pensamento educacional em Marx e Gramsci e a concepção de politecnia. https://www.scielo.br/j/tes/a/GTK93QB5JvKdccpjXjyfNyP/?lang=pt.

Freire, P. (2014).. Pedagogia da esperança: um reencontro com a pedagogia do oprimido. Editora Paz e Terra.

Frigotto, G. \& Ciavatta, M. (2005). (Orgs). A experiência do trabalho e a educação básica. (2a ed.) DP\&A,

Gohn, M. G. (2011). Movimentos sociais na contemporaneidade. Revista Brasileira de Educação,16(47) maio-ago. https://www.scielo.br/j/rbedu/a/vXJKXcs7cybL3YNbDCkCRVp/?format=pdf\&lang=pt.

Júnior, Marco Antonio Mitidiero. Violência no campo brasileiro em tempos de golpe. Boletim DATALUTA n. 114 - Artigo do mês: junho de 2017. http://www2.fct.unesp.br/nera/artigodomes/6artigodomes_2017.pdf.

Kolling, J.E., Cerioles, P. R. \& Caldart, R. S. (2002). (Orgs.). Educação do campo: identidades e políticas públicas. Brasília: Articulação Nacional por uma Educação do Campo, 2002. (Coleção por uma educação do campo, no 4). http://www.forumeja.org.br/ec/files/Vol\%204\%20Educa\% C3\%A7\%C3\%A3o\% 20B\%C3\%A1sica\%20do\%20Campo.pdf.

Ludke, M. \& André, M. (2013). Pesquisa em educação: abordagens qualitativas. (2a ed.) E.P.U.

Medeiros, M. O. de. (2012). Novos olhares, novos significados: a formação de educadores no campo. Tese de doutorado. Universidade de Brasília, Faculdade de Educação.2012. https://repositorio.unb.br/bitstream/10482/12235/1/2012_MariaOsanetteMedeiros.pdf.

Mészáros, I. (2008). A educação para além do capital. Trad. Isa Tavares. (2a ed.) Boitempo, (Mundo do trabalho).

Miranda, A P. M. (2009). Movimentos sociais, a construção de sujeitos de direitos e a busca por democratização do estado. Universidade Católica de Petrópolis. 2009. https://app.uff.br/riuff/bitstream/handle/1/6105/LH1-1artigo10.pdf;jsessionid=45FE8A5067C1E4C3FC37108FCA3FF519?sequence=1 .

Minayo, M. M. S. (2002). Pesquisa social: teoria, método e criatividade. Editora Vozes, 2002. https://wp.ufpel.edu.br/franciscovargas/files/2012/11/pesquisa-social.pdf

Nosella, P. (2012). Educação no campo: origens da pedagogia da alternância no Brasil. Vitória: EDUFES, 2012. (Educação do campo. Diálogos interculturais).

Paro, V. H. (2010). Educação como exercício do poder: crítica ao senso comum em educação. (2a ed.) Cortez.

Saviani, D. (2012). Prefácio. In: Nosella, Paolo. Educação no campo: origens da pedagogia da alternância no Brasil. Vitória: EDUFES. (Educação do campo. Diálogos interculturais)

Semeraro, G. (2006). Gramsci e os novos embates da filosofia da práxis. Aparecida: Ideias \& letras. 
Research, Society and Development, v. 11, n. 3, e5011326096, 2022

(CC BY 4.0) | ISSN 2525-3409 | DOI: http://dx.doi.org/10.33448/rsd-v11i3.26096

Silva, T. S. da (2016). Didática e o ensino de filosofia. Pelotas: NEPFIL, online, http://nepfil.ufpel.edu.br

Vergutz, C. L. B. \& Cavalcante, L. O. H. (2014). As aprendizagens na pedagogia da alternância e na educação do campo. Reflexão e Ação, Santa Cruz do Sul, 22(2), 371-390. https://online.unisc.br/seer/index.php/reflex/article/viewFile/5057/3697 